\title{
Methods to Expand the Speed and Load Range of Homogeneous Charge Compression Ignition Engine
}

\author{
Martin Šima* , Peter Bigoš, Roman Tonhajzer \\ Technical university of Košice, Faculty of Mechanical Engineering, Department of Machine Design, Transport and Logistics Letná 9, 04001 \\ Košice, Slovak Republic
}

\section{BIOGRAPHICAL NOTES}

Ing. Martin Šima, is an internal Phd. student at the Department of Machine Design, Transport and Logistics at the Faculty of Mechanical Engineering, Technical University of Košice. His dissertation topic is: New methods for improving the efficiency of internal combustion engines. He is focusing on improving mainly the thermal efficiency via homogenous charge compression ignition, where lower combustion temperature can be obtained.

prof. Ing. Peter Bigoš, CSc., is a university professor nominated in the branch of science "Transport and Handling Engineering". He is a head of the Department of Machine Design, Transport and Logistics at the Faculty of Mechanical Engineering, Technical University of Košice. He graduated at the Faculty of Mechanical Engineering of the former Technical College in Košice (1973). Dissertation thesis he defended in 1980 and in 1983 he was designated as a docent (associate professor). In 1991 he defended his inaugural dissertation at the Technical University of Košice. In the framework of his study stages he visited TU Miskolc, VH Dresden (1981), Polytechnika Rzeszowska (1983), Ruhr Universität Bochum (1989), Imperial College London (1993), TU Budapest (1997). He is a vice-chairman of the "Common professional commission for PhD.-study" in the branch of study "Transport Machines and Machinery" and he is a member of professional commission in the branch "Forensic Engineering", too. He is also member of several advisory boards of domestic and foreign professional journals, as well as he is a guarantor of international and domestic conferences about transport machines and logistics.

Ing. Roman Tonhajzer, is an internal Phd. student at the Department of Machine Design, Transport and Logistics at the Faculty of Mechanical Engineering, Technical University of Košice. He graduated in 2012 with theme of his diploma thesis: Optimalization fuel maps and data of control unit for four stroke combustion engine. At present he dedicated to the research and development of piston combustion engines, singletrack transport means and application research for racing motorcycles.

\section{KEYWORDS}

Homogenous charge compression ignition, active thermo atmosphere combustion, variable compression ratio, spark ignition engine, compression ignition engine.

\section{Introduction}

Internal combustion engines are the most widespread devices where the chemical energy contained in fuel is transforming into output work. Considering the facts 
of stricter emission standards and world fuel consumption engineers are always looking for alternative sources of energy. The concept of homogeneous charge compression ignition ( $\mathrm{HCCl}$ ) has the ability to reduce both - emissions and fuel consumption. $\mathrm{HCCl}$ engine can be described as a hybrid between spark ignition (SI) and compression ignition $(\mathrm{Cl})$ engine. It incorporates the best features of both of them. Comparing to the $\mathrm{Cl}$ engines it is producing lower emissions (mainly NOx), while it has better efficiency than the SI engines. In $\mathrm{HCCl}$ engines the homogenous mixture of air and gasoline is burning. Temperature of this mixture is increasing during the compression stroke and autoignition near the top dead centre (TDC) occurs. Ignition of the mixture takes place simultaneously throughout the whole volume there is no spread of flame as in $\mathrm{Sl}$ engines. $\mathrm{HCCl}$ engines can run on variable fuels (petrol, diesel, propane, natural gas).

This concept was described for the first time in 1979 by Onishi et al. at a research institution Nippon Clean Engine. They called the combustion process as ATAC (active thermo atmosphere combustion). It was a two stroke gasoline engine, working with lean mixtures. First results with four stroke engine

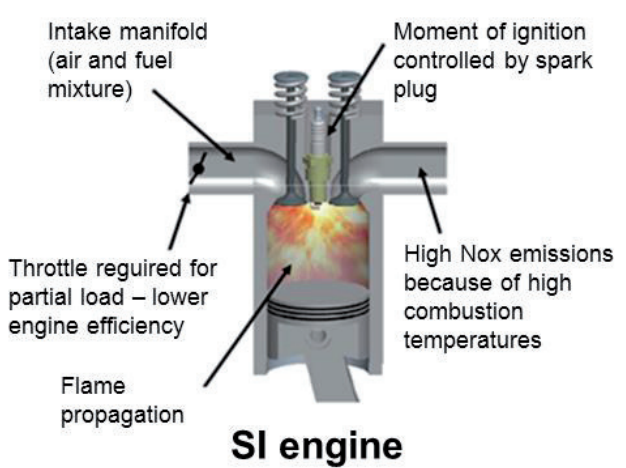

were succeeded by Najt and Foster in 1983. HCCl combustion was achieved by external air heating. Better efficiency and lower fuel consumption was described, but only in laboratory conditions.

Aim of this paper is to expand the operating range suitable for $\mathrm{HCCl}$ combustion by using variable compression ratio and throttling the exhaust valve to trap residual gases in cylinder.

\section{Experimental Section}

In SI engines load is controlled by throttling the amount of air and gasoline entering in to the cylinder, combustion is timing by the spark event from spark plug. SI engines suffer of the lower efficiency at part load because of throttling. In Cl engines autoignition is timing by the moment of opening injectors, load is controlled by the amount of fuel injected into the hot air. The biggest issue of $\mathrm{HCCl}$ engine is to control the time when autoignition occurs thru the various speed and load range. There is no possibility how to control the auto-ignition directly, it can be done only indirectly by following strategies:

\section{External heating of air entering the cylinder. 2.Using variable compression ratios (VCR).}

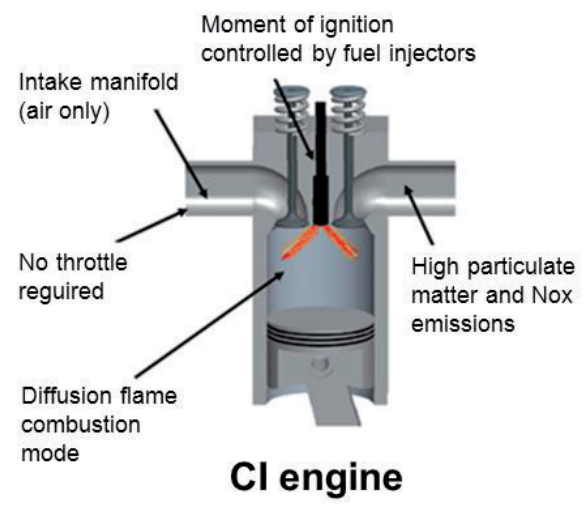

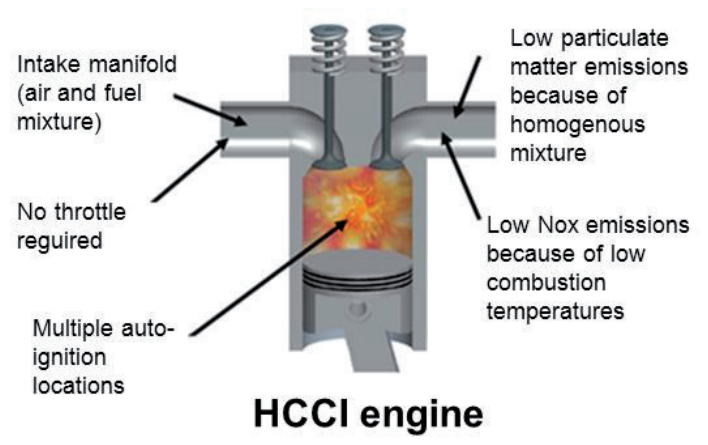

Fig. 1: Confrontation of SI, Cl and HCCl engine. 
3.More auto-ignitable fuels.

\section{Intake the residual gases from previous cycle - ex- haust gas recycling (EGR).}

Another problem is very high combustion rate, because the whole mixture auto-ignites at the same time. There is no flame propagation. This disadvantage can be solved by previous strategies and adjusting the parameters correctly. Also water injection can be used to slow down the combustion rate. Confrontation of $\mathrm{SI}, \mathrm{Cl}$ and $\mathrm{HCCl}$ engines is shown in Fig. 1.

The main reason why $\mathrm{HCCl}$ engine did not replace $\mathrm{SI}$ and $\mathrm{Cl}$ engines in mass production is the speed, load operation limit and cold start capability. In these conditions $\mathrm{HCCl}$ combustion is not possible and a spark plug must be used. Figure 2, which was published by Onishi, shows the operational range suitable for ATAC combustion. The most important factor is high average temperature in the cylinder, which can be achieved by using residual gases from previous cycle. At very low load, the average temperature is decreasing what makes the ATAC combustion impossible. By increasing the load of engine suitable conditions for ATAC combustion ensues. At high engine load more proportion of fresh charge is necessary and thus average temperature is decreasing again. To ignite the charge the spark plug must be used.

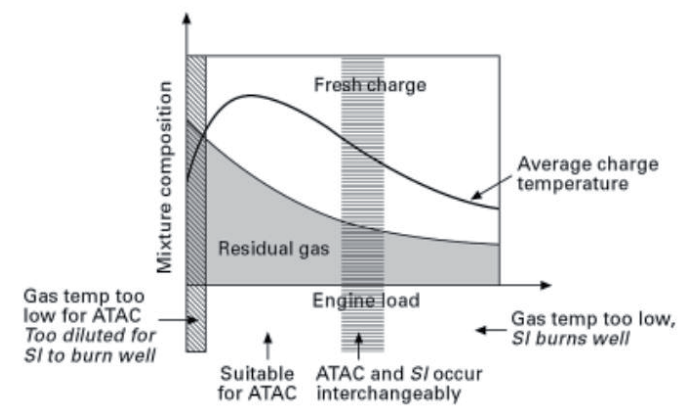

Fig. 2: Operational range of ATAC combustion.

A two-stroke, water-cooled $125 \mathrm{ccm}$ bike gasoline engine was employed. On this engine following constructional modifications must be done to achieve $\mathrm{HCCl}$ :

1. Split the head of engine to ensure VCR. Change of compression ratio can be realized by changing the position of secondary piston in the head using hydraulic system. This allows changing the compression ratio from 5,8:1 to $23,7: 1$ by traveling the secondary piston up and down $9 \mathrm{~mm}$. The cooling channels must be also divided see Fig. 3 .

2. Modified the original RC valve to trap residual gases in cylinder. This was done to avoid the need of external air heating. Many previous experiments used electrical heater, but did not count the electrical power into efficiency calculations.

The original compression ratio of the engine was $6,8: 1$ and volume was $124,8 \mathrm{ccm}$. The clearance volume is:

$$
V_{c}=\frac{V_{S}}{C R-1}=\frac{\frac{\pi}{4} \cdot b^{2} \cdot s}{C R-1}=\frac{\frac{\pi}{4} \cdot 5,4^{2} \cdot 5,45}{6,8-1}=21,52 \mathrm{ccm}(1)
$$

Where: $V_{s}$ - swept volume, $V_{c}$ - clearance volume, $\mathrm{CR}$ - compression ratio, b - cylinder bore (diameter), s - piston stroke (length).

In the modified engine the clearance volume can be adjust to $+2 \mathrm{~mm}$ and $-7 \mathrm{~mm}$ toward to the initial position. The compression ratio can acquire following values.

$$
\begin{aligned}
& C R_{\min }=\frac{V_{s}+\left(V_{c}+\frac{\pi}{4} \cdot b^{2} \cdot z\right)}{V_{c}+\frac{\pi}{4} \cdot b^{2} \cdot z}=\frac{124,8+\left(21,52+\frac{\pi}{4} \cdot 5,4^{2} \cdot 0,2\right)}{21,52+\frac{\pi}{4} \cdot 5,4^{2} \cdot 0,2}=5,8(2) \\
& C R_{\max }=\frac{V_{s}+\left(V_{c}-\frac{\pi}{4} \cdot b^{2} \cdot z\right)}{V_{c}-\frac{\pi}{4} \cdot b^{2} \cdot z}=\frac{124,8+\left(21,52-\frac{\pi}{4} \cdot 5,4^{2} \cdot 0,7\right)}{21,52-\frac{\pi}{4} \cdot 5,4^{2} \cdot 0,7}=23,7(3)
\end{aligned}
$$

Experiments with 2-stroke engine running in AR (active radical combustion) have been done in 1995 by Honda. They used only the AR valve to throttle the exhaust gases, without changing compression ratio. The spark plug must be used to run the engine when the throttle openings greater than 40 percent.

To run the engine in $\mathrm{HCCl}$ mode the engine management must be replace, except the constructional modifications. To monitor the actual cylinder pressure the spark plug was removed and replace by pressure sensor. Also the charge temperature, inlet air temperature, pressure, compression ratio (CR) and fuel supply must be monitored. For each cycle the $C R$ and throttle valve must be adjust to get the $\mathrm{HCCl}$ combustion near top dead center (TDC). When the charge temperature is increasing the CR must be lowered and conversely.

\section{Results and Discussion}

By adjusting the compression ratio, trapping propriety amount of residual gases in cylinder and correct motor management $\mathrm{HCCl}$ combustion can be attained over various speed and load range, for 


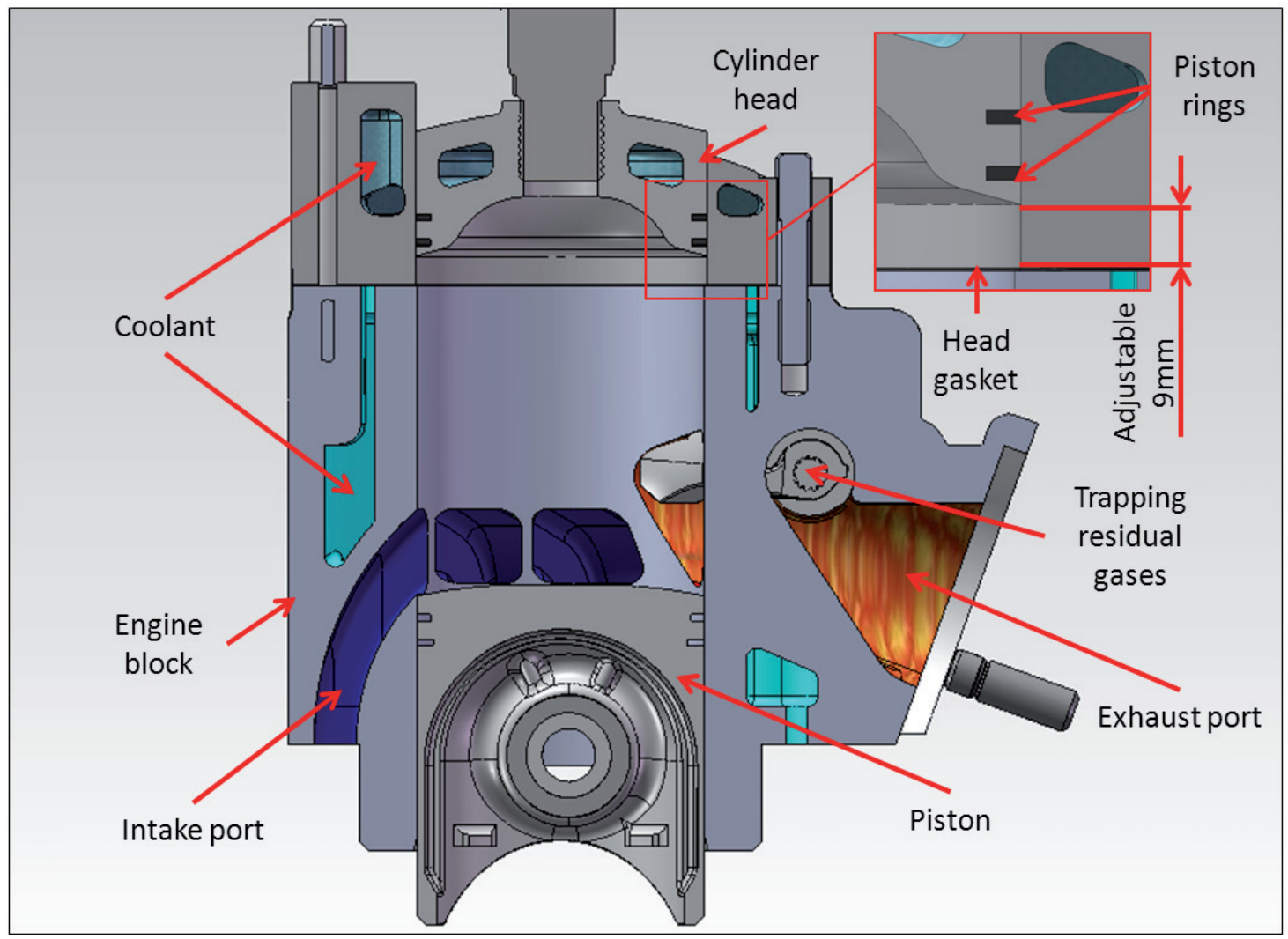

Fig. 3: Modified head of two stroke engine.

constant fuel octane number. The key advantages of $\mathrm{HCCl}$ engines are: low NOx emission, high efficiency (Fig.4). Comparing with $\mathrm{SI}$ engines $\mathrm{HCCl}$ engine can have approximately $15 \%$ better efficiency. Since the combustion temperature is lower than in $\mathrm{SI}$ or $\mathrm{Cl}$ engines, less heat is transfer to cylinder walls and piston, the heat loses are reduced. That is why thermal efficiency is increasing. NOx emission also depends on how long the gases are exposed high temperature. $\mathrm{HCCl}$ engines are working with homogenous lean mixture, there are not rich zones like in $\mathrm{Cl}$ engines (where NOx is generated). Low temperatures are expected to be the same in all combustion chamber, expect near piston and walls. Therefor NOx emissions are decreasing.

Temperature of $\mathrm{HCCl}$ engines is so low that the fuel cannot oxidize completely and even the catalytic reaction in the catalyst will not occur. This results in high $\mathrm{HC}$ emissions. This will probably require further development of the oxidation catalytic converter, which will be able to work with low temperature.
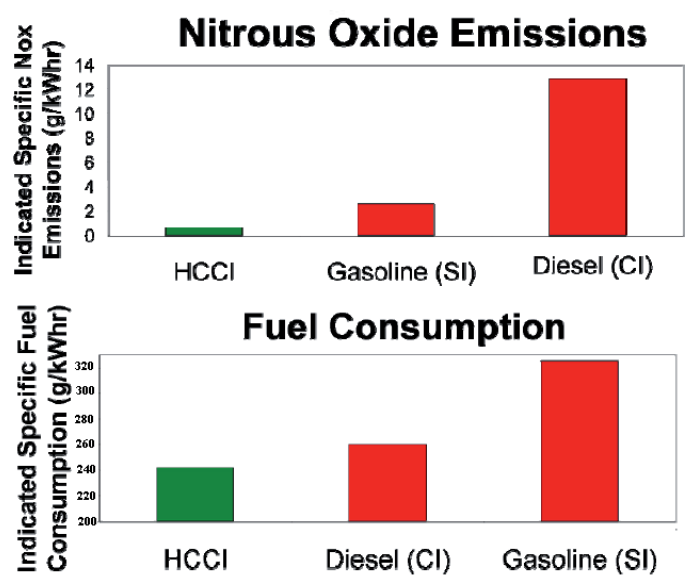

Fig. 4: Fuel consumption and NOx emissions of Cl, SI and HCCl engine.

Neither using both variable compression ratio and trapping residual exhaust gases cannot give $\mathrm{HCCl}$ combustion over the entire range of load and speed. The load can be limited by knocking the engine. On the other hand when the load is very low, higher amount of residual gases has to be trapped 
in cylinder. The temperature is getting lower because of previous cycles and misfire follows, the mixture failed to auto-ignite. At higher speeds the gas exchange can be a limiting factor.

Consequently we are suggesting using the continuously variable transmission (CVT) in cooperation with $\mathrm{HCCl}$ engine. This can be the key solution how to make the engine work in stable $\mathrm{HCCl}$ combustion over the whole period. If an engine can for example give stable $\mathrm{HCCl}$ combustion only in range of load: 1 - 4,3 bar BMEP and speed 1000 - 5000 rpm. The CVT gearbox control unit will modifies the engine to run only in a given range, also take in consideration the drivers requirements. The gear ratio range is 7 . Despite the fact that overall efficiency of CVT transmission is lower, approximately $90 \%$, the combination of $\mathrm{HCCl}$ engine and CVT transmission will play role in the future.

There are two reasons why the two-stroke engine was chosen for the rebuilt to work in $\mathrm{HCCl}$ mode: It's simplicity of construction. The second reason is based on allegations that 15 largest cruise ships pollute the air as much as all cars in the world. These ships have two-stroke diesel engine.

\section{Conclusion}

Low fuel consumption, low emissions, lower combustion temperature, all these aspects provide these engines their place in the near future. Also concerns of automakers (GM, MERCEDES BENZ), which are investing in development the $\mathrm{HCCl}$ engine a considerable amount of financial resources, suggest this. However, many technical problems associated with their operation, like cold start capability, formation of homogenous charge, limited operating mode, must be solved. In this paper it has been demonstrated how to solve the major problem of $\mathrm{HCCl}$ engines, which is controlling the ignition timing over various speed and load range. This ignition timing cannot be controlled directly like in $\mathrm{Sl}$ or $\mathrm{Cl}$ engines. There are a lot of possibilities how to affect the auto-ignition, anyway changing the compression ratio and trapping residual gases in cylinder are the strongest one. Changing these two parameters with sufficient response, $\mathrm{HCCl}$ combustion range can be expanded. Along with the support of CVT transmission the $\mathrm{HCCl}$ combustion can be accomplished at any circumstances.

\section{Acknowledgments}

At the present time the problem is solved in the framework project "VEGA 1/0197/14 New Methods of Efficiency Increasing and Emission Reductions for Driving Unit of Transport Vehicle Using Innovation of Main Components and Consequent Optimization of Production Process of them with Consideration of Possible Production and Operation Risk".

\section{References}

[1] Puškár, M. ... [et al.]. Measuring method for feedback provision during development of fuel map in hexadecimal format for high-speed racing engines. In: Measurement. Vol. 50, no. 1 (2014), p. 203-212. - ISSN 0263-2241.

[2] Šima, M. Vývoj spalovacích motorov. In: MotoReport. Roč. 11, č. 6 (2013), s. 40-41. - ISSN 1336-3317.

[3] Zhao, H. Hcci and Cai Engines for the Automotive Industry. Brunel University, UK: Woodhead Publishing Limited, 2007. str. 544. ISBN 1845691288.

[4] Martins, M, Zhao, H. Performance and emissions of a 4-cylinder gasoline engine with Controlled Auto-Ignition. In: Journal of the Brazilian Society of Mechanical Sciences and Engineering. Vol.34, no. 4 (2012). - ISSN 1678-5878 
Acta Mechanica Slovaca

Journal published by Faculty of Mechanical Engineering - Technical University of Košice

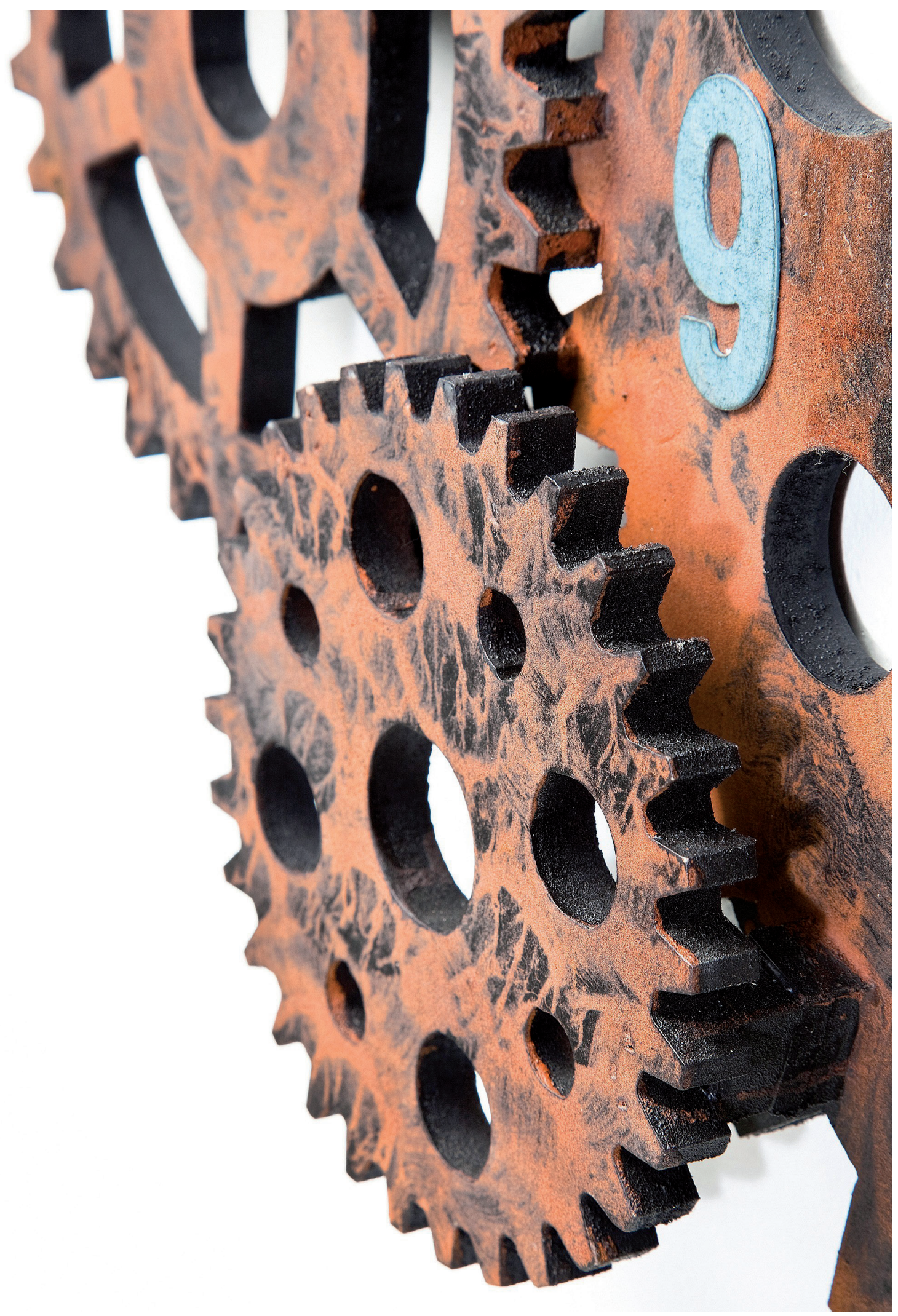

